\title{
Cardiovascular system and coronavirus disease-2019 (COVID-19): mutual injuries and unexpected outcomes
}

\author{
Eman Sobh ${ }^{1,2^{*}} \mathbb{D}$, Muhammad Saad Reihan ${ }^{3,4}$, Tamer M. S. Hifnawy ${ }^{5}$, Khloud Gamal Abdelsalam ${ }^{6}$, \\ Sohaila Sabry Awad ${ }^{7}$, Nehal Mostafa Hamed Mahmoud ${ }^{8}$, Nariman A. Sindi ${ }^{9}$ and Hani A. Alhadrami ${ }^{9,10}$
}

\begin{abstract}
Background: Cardiovascular system involvement in coronavirus disease-2019 (COVID-19) has gained great interest in the scientific community.

Main body: Several studies reported increased morbidity and mortality among COVID-19 patients who had comorbidities, especially cardiovascular diseases like hypertension and acute coronary syndrome (ACS). COVID-19 may be associated with cardiovascular complications as arrhythmia, myocarditis, and thromboembolic events. We aimed to illustrate the interactions of COVID-19 disease and the cardiovascular system and the consequences on clinical decision as well as public health.
\end{abstract}

Conclusions: COVID-19 has negative consequences on the cardiovascular system. A high index of suspicion should be present to avoid poor prognosis of those presenting with unusual presentation.

Keywords: Coronavirus disease, SARS-CoV-2, Cardiovascular dysfunction, Cardiovascular function, Public health implications

\section{Background}

Coronavirus disease-2019 pandemic is a major health problem that affected hundreds of countries and territories. It results in more than 200 million infected cases and more than four million deaths worldwide [1]. COVID-19 is caused by a novel strain of coronaviruses called severe acute respiratory syndrome coronavirus-2 (SARS-CoV-2) [2]. It is well established now that SARS-CoV2 has pulmonary as well as extrapulmonary effects [3], including renal, cardiac, nervous and gastrointestinal systems [3, 4]. Mutual interaction is present between COVID-19 and the cardiovascular system (Fig. 1). A link exists between cardiovascular (CV) comorbidities and both COVID-19

\footnotetext{
*Correspondence: emansobh2012@gmail.com; emansobh@azhar.edu.eg; esobh@taibahu.edu.sa

${ }^{1}$ Chest Diseases Department, Faculty of Medicine for Girls, Al-Azhar University, Cairo, Egypt

Full list of author information is available at the end of the article
}

risk and outcome [5-7]. CV comorbidities were associated with disease severity and a greater risk of death $[8$, 9]. At the same time, COVID-19 was associated with several cardiovascular complications [10]. These cardiovascular complications include: venous thromboembolism (VTE), pulmonary embolism (PE), myocarditis, arrhythmias, ACS, and sudden cardiac arrest $[9,11,12]$. PE is the most devastating complication expected in severe COVID-19 disease [9]. In this review, we will illustrate the interaction between COVID-19 and the cardiovascular system, the mutual complications, and the impacts of COVID-19 on clinical decision-making and public health.

\section{Main text}

Pathophysiology of cardiovascular injury in COVID-19 Severe acute respiratory syndrome coronavirus 2 (SARS-CoV2) infection is the cause of COVID-19 [6]. 


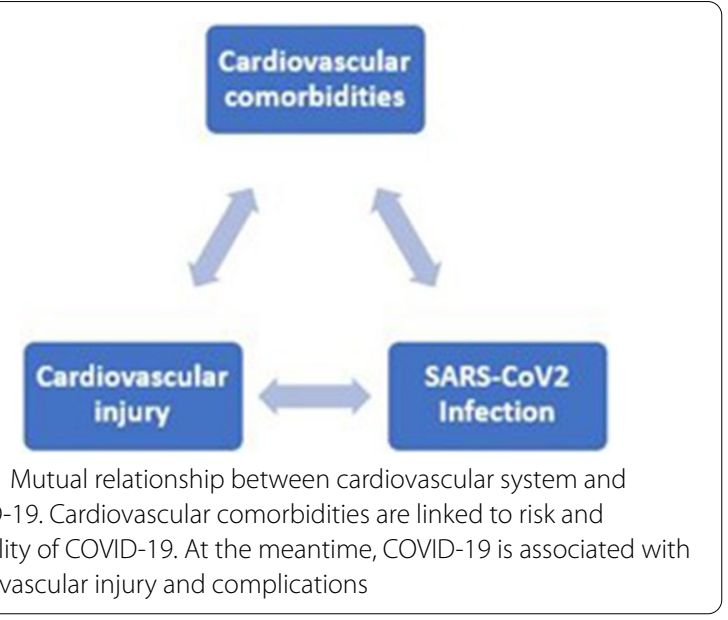

SARS-CoV-2 uses a spike protein $\mathrm{S} 1$ to enable the attachment of the virion to the cell membrane of the host and then mRNA encoding several other proteins, by interacting with the host angiotensin-converting enzyme 2 (ACE2) receptors [13]. Besides, the SARS-CoV2 spike protein has a 10-20-fold binding affinity to the human ACE2 receptor higher than that of the SARS-CoV the causative agent of SARS disease which explains the high contiguity of the SARS-CoV2 [14]. ACE2 receptors are expressed principally in type II pneumocytes which are considered the predominant gateway for SARS-CoV-2 entry [6]. ACE2 receptors and transmembrane protease serine 2 (TMPRSS2) are expressed in different body systems like the gastrointestinal, urinary, and reproductive organs $[3,15]$. It has been found that ACE2 receptors are highly expressed in the cardiovascular tissue including endothelial cells, cardiac myocytes, fibroblasts, and smooth muscle cells $[6,16,17]$. ACE2 receptors were presumed to counteract the effects of angiotensin II in cases associated with the renin-angiotensin system (RAS) overactivity, such as hypertension, atherosclerosis, and congestive heart failure (HF). Thus, according to this, there is a direct relationship between COVID-19 and increased deaths and morbidity from cardiovascular disease (CVD) [6]. Furthermore, higher expression of ACE2 may facilitate penetration of the virus into the cell, prolong the virus life cycle, and enhance virus replication [18]. The exact mechanism of cardiovascular involvement in COVID-19 is still unclear, and several mechanisms have been proposed [3, 19]; it may be a result of direct or indirect injury [3]. Direct myocardial injury may result from direct viral toxicity through binding to ACE2 receptors present in the cardiac muscle [3, 19]. Pathological examination of COVID-19 autopsies confirmed the presence of SARS-CoV2 viral copies in the myocardium as well as other organs including the endothelial cells of the venous and arterial system (orgamotropism) [20-22]. The spread of infection to the myocardium and other organs is still unclear and thought to be through hematogenous spread (viremia) [20].

Indirect cardiac injury may be attributed to immune system dysregulation with the release of cytokines, thrombo-inflammation, microcirculation dysfunction, endothelial cell damage, and dysregulation of the reninangiotensin-aldosterone system (RAAS) [3]. Cardiac injury can result from the abnormal systemic inflammatory response with exaggerated secretion of inflammatory mediators (cytokine storm). These inflammatory markers include: interleukin (IL-) 1B, IL-2, IL-6, tumor necrosis factor-alpha (TNF- $\alpha$ ) [23, 24], monocyte chemoattractant protein-1 (MCP-1) [23]. This cytokine storm is enhanced in the presence of aberrant $\mathrm{T}$ helper cells immune response and the increased intracellular calcium secondary to hypoxia. The net result is cardiac myocyte apoptosis [23]. Inflammatory cell infiltration of the myocardium was detected in several autopsy studies $[25,26]$. Myocarditis is a significant factor in patients with acute HF [11].

A preexisting cardiovascular disease is a risk factor for severe COVID-19 due to increased expression of ACE2 receptors $[27,28]$. Increased pulmonary pressure in respiratory failure and ARDS may result in right ventricular dysfunction $[29,30]$. Pulmonary thromboembolism can be considered as another important factor $[31,32]$.

Physiologic stress with hypoxemia is a contributing factor that may result in myocardial ischemia, tachycardia, and several cardiovascular adaptations [33-35].

Partly, arrhythmias may be attributable to hypoxia, inflammatory stress, and abnormal metabolism in SARS$\mathrm{CoV}$-2-infected patients with or without preexisting CVD [36]. Various types of arrhythmias may result as a side effect of drugs used in treatment COVID-19 [11]. Several studies reported arrhythmias in cases with severe COVID-19 pneumonia due to gas exchange abnormalities secondary to hypoxemia [37, 38]. Dysrhythmia may further complicate the disease course [11].

Hypoxemia is associated with a significant reduction in the energy supply and increases anaerobic metabolism resulting in intracellular acidosis and excess oxygen free radicals that destroy the cell membrane [37, 38]. As a consequence of systemic infection and hypoxia, cardiometabolic demand is elevated, and in the presence of inadequate supply, myocardial oxygen supply/demand mismatch occurs leading to myocardial damage [39].

Malavazos et al. proposed that the epicardial adipose tissue (EAT) contributes to the development of myocarditis. EAT has a direct anatomical and functional relationship to the myocardium, and both share the same microcirculation. During SARS-CoV2 infection, EAT is 
highly infiltrated with macrophages and cytokines like IL-6 which can reach the pericardium and myocardium directly via the vasa vasorum or through paracrine pathways [40].

The hypercoagulable state was a prominent finding in COVID-19 patients in several reports. Laboratory findings in these patients included: high serum ferritin [7]. High levels of D-dimers, fibrinogen, CRP decide prolonged prothrombin time (PT). Fibrinogen levels may decrease in advanced disease. Leukopenia, lymphopenia, and thrombocytopenia are also common features [41, 42].

Increased morbidity and mortality in COVID-19 may be attributed to several risk factors including male gender, old age, obesity, hypertension, diabetes, and established cardiovascular and cerebrovascular disease [7, 43]. Poor outcome in these patients can be explained by uncontrolled viral replication and prolonged pro-inflammatory response as a result of the excess secretion of type 2 cytokines and the age-related T-cell and B-cell dysfunction [43]. Further, older age and male sex were associated with an increased level of expression of ACE2. The upregulation of ACE2 has been reported as significantly high in patients with diabetes mellitus (DM) and hypertension who receive ACE inhibitors (ACEIs) or angiotensin receptor blockers (ARBs) $[44,45]$. These results led to the assumption that those patients are more susceptible to infection with SARS-CoV2. ACE2 polymorphisms are more likely to be a hereditary risk of developing infection with COVID-19 [46]. VTE in COVID-19 may result from abnormal coagulation, systemic inflammatory response, multiorgan dysfunction, critical illness [47], hormonal therapy, prolonged bed rest, and immobilization [48]. Prolonged hospitalization with decreased mobility and severe respiratory disease are also risk factors for VTE [49]. Even lockdown has been associated with increased risk of CVD [50].

\section{Cardiovascular comorbidities in COVID-19}

Comorbid illnesses are prevalent in severe COVID19 cases. Cardiovascular comorbidities were reported to be a key player due to its effect on prognosis. It has been reported that CVD increased the case-fatality rate by $10.5 \%$, compared to $7.3 \%, 6.3 \%, 6 \%$, and $5.6 \%$ for $\mathrm{DM}$, chronic obstructive pulmonary disease (COPD), hypertension, and cancers, respectively [51]. Similar behavior was noted for MERS-CoV and SARS [52, 53]. Patients with CVD have increased susceptibility to infection with COVID-19 and are prone to serious and complicated symptoms [54].

\section{Cardiovascular complications COVID-19}

Management of myocardial dysfunction during the current pandemic is a great challenge. Several factors are to be considered including the challenges to perform cardiac imaging, hemodynamic assessment, and endomyocardial biopsies on the one side and the hazard of viral infection to patients and healthcare professionals (HCP) as well as contamination of healthcare facilities on the other side $[55,56]$.

Cardiac involvement may occur several days after influenza-like symptoms [57]. The frequency of cardiovascular symptoms in COVID-19 is still unknown. Most patients develop gradual deterioration. The median interval between the onset of symptoms and admission to ICU ranged between 9 and 10 days [58]. Chest pain or tightness with or without breathlessness is the most common symptom, and pain is usually poorly localized. Myocardial infarction type II may be suspected if chest pain and ECG changes are associated with altered biomarkers[35]. Typical symptoms related to myocardial ischemia are more reported in ACS patients [35].

A large spectrum of CV complications can develop in COVID-19 patients (Fig. 2). Patients with COVID-19 may present with various cardiovascular conditions as cardiomyopathy (either stress or non-ischemic), ACS, AMI, myocarditis simulating a stable ST-segment elevation myocardial infarction (STEMI), myocardial injury without evidence of Type I or Type II AMI [51, 59], pulmonary thromboembolism, acute corpulmonale, isolated right ventricular failure, and cardiogenic shock (CS) [3, 31, 32], cardiac arrhythmias [60], and heart failure [59]. Critically ill patients may develop pneumonia, ARDS, multi-organ dysfunction, hemodynamic instability, and several cardiovascular complications [51, 59].

\section{Acute myocardial injury}

Myocardial injury is defined as a remarkable rise in troponin levels. It may occur due to ischemic or nonischemic myocardial injury as myocarditis [61]. Acute myocardial injury evidenced by elevated cardiac biomarkers, characteristic ECG, and new imaging features of impaired cardiac function was recognized among COVID-19 cases and is suspected to occur in patients who had hypoxia or ARDS [6, 43]. Myocarditis may be the initial presentation in some cases [62].

\section{Acute myocardial infarction (AMI)}

Increased incidence of AMI has been reported with several respiratory viruses including influenza and other coronavirus species [63]. Severe inflammation and hypercoagulation increase the likelihood of AMI in patients with COVID-19 [64]. Acute myocardial infarction (AMI) is an urgent situation that requires emergency 


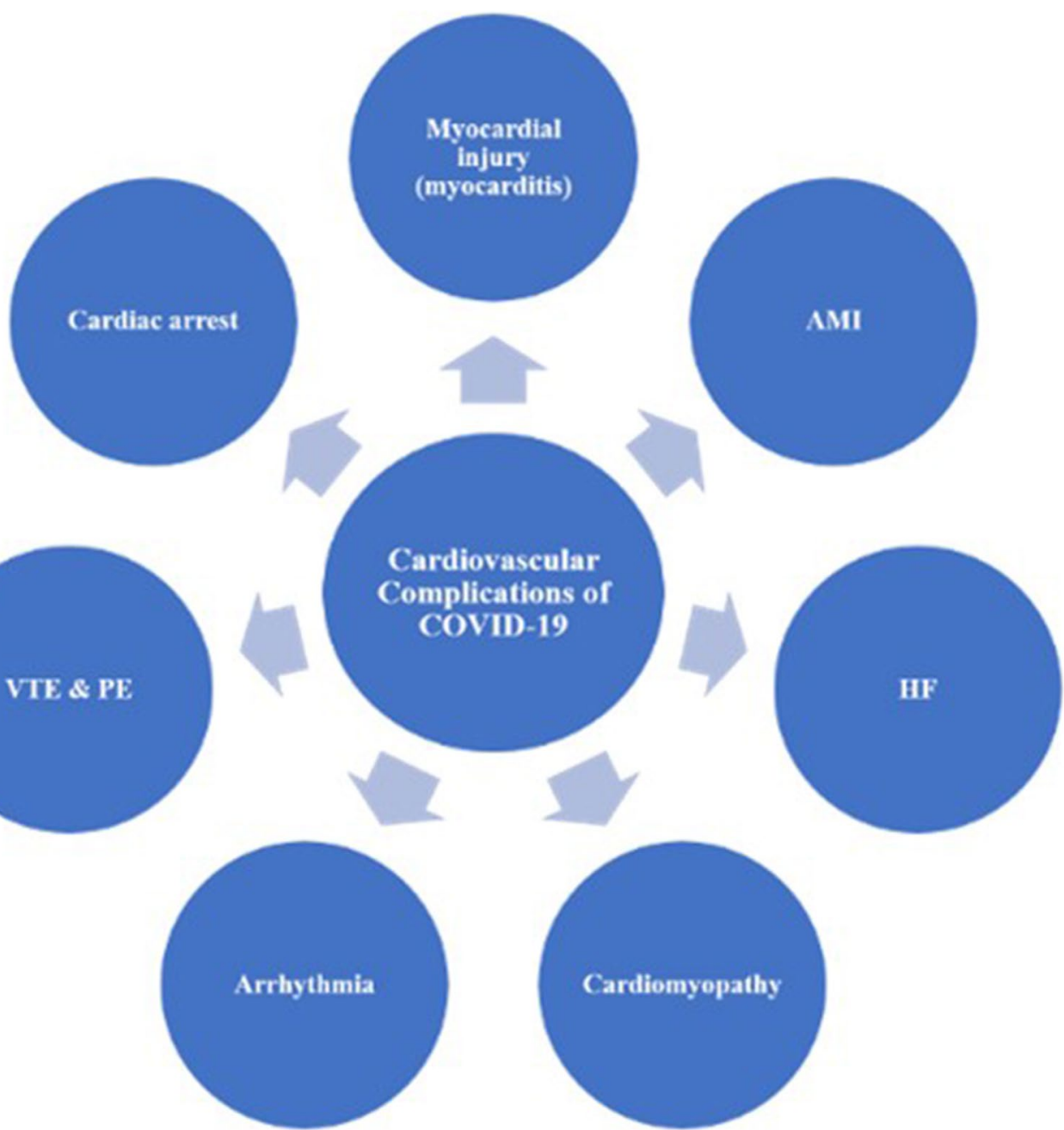

Fig. 2 Spectrum of cardiovascular complications in COVID-19. A wide spectrum of cardiovascular complications in COVID-19 is reported. AMI: acute myocardial infarction; HF: hear failure; VTE: venous thromboembolism; PE: pulmonary embolism

management. Infection with SARS-COV-2 greatly affected AMI diagnosis and treatment [64]. SARS-CoV-2 infection can result in several cardiovascular manifestations even without respiratory symptoms or constitutional manifestations like fever and bony aches [57].

\section{Heart failure (HF) and cardiomyopathy}

Heart failure may be the principal clinical feature of COVID-19 infection [10, 62]. The frequency of HF in COVID-19 patients varies from 0.4 to $43 \%$ in previous reports [65]. Myocardial damage and HF accounted for nearly $40 \%$ of deaths in critically hospitalized patients [59].

\section{Cardiac arrhythmia}

Arrhythmias may associate or complicate COVID-19 infection [10]. Palpitations have been reported by some patients, and sinus tachycardia was the most common type of dysrhythmia observed [66]. Hypoxemia in COVID-19 patients can trigger AF, particularly in the elderly [67]. A cohort study in China demonstrated that cardiac dysrhythmia was present in $16.7 \%$ of hospitalized patients with COVID-19. The frequency among ICU patients was $44.4 \%$ compared to $6.9 \%$ for non-ICU patients [60]. Several types of cardiac arrhythmias were also reported including ventricular arrhythmias, newonset atrial fibrillation (AF), and heart block [60].

\section{Venous thromboembolism (VTE) and pulmonary embolism} Patients suffering from COVID-19 infection are also at high danger of developing VTE. Thrombotic events were more probable in critically ill COVID-19 patients despite the use of proper anticoagulation [48]. Cui et al. reported $25 \%$ of hospitalized patients with COVID-19 had DVT of 
lower extremities. No anticoagulation had been administered to those patients [41]. Bompard et al. [68] and Grillet et al. [69] observed PE in nearly one-fourth of patients with COVID-19 pneumonia who underwent contrastenhanced CT pulmonary angiography. Also, autopsies from patients who died from COVID-19 showed pulmonary microthrombi [70]. Thrombosis in COVID-19 may be attributed to hypercoagulable state associated with inflammatory process resulting in endothelial activation and dysfunction, platelet activation leading activation of coagulation cascade. Abnormalities in renin-angiotensin system associated with COVID-19 result in vasoconstriction and cytokine release which promote thrombosis. moreover, the tissue damage due to cytokine storm and weak immune system increase the risk of thrombosis [71].

\section{Cardiac arrest}

Researchers reported an increased incidence of out-ofhospital cardiac arrest during the COVID-19 pandemic in 2020 compared to the same period during 2019 [12]. Several reports of cardiogenic shock [62] or sudden cardiac arrest in COVID-19 patients had been published [72].

\section{Diagnostic tools}

\section{Electrocardiogram (ECG) in COVID-19 patients}

No specific ECG changes are described in COVID-19 patients. This may be attributed to the subtle myocardial involvement associated with infection [57]. So, the same ECG diagnostic criteria in the general population are applied for COVID-19 patients [60]. ST-segment elevation was reported in myocarditis [57]. Arrhythmias were reported in various percentages of patients especially those who were admitted to ICU [60]. Prolonged QT ( $>500 \mathrm{~ms}$ ) was detected at the time of hospitalization in $6.1 \%$ of patients with COVID-19 in a multicenter research [73]. New ECG changes may indicate cardiac complications especially in those with elevated biomarkers [43]. ECG should be done to record the patient's baseline QT interval before receiving drugs that may prolong QT interval [74].

\section{Imaging}

Any elective cardiac imaging should be delayed until the patient is considered non-infectious [75]. Transthoracic echocardiography is the recommended investigation for hospitalized patients with HF, suspected MI, new ECG changes, or newly diagnosed cardiomegaly in chest imaging. Cardiac CT and MRI are helpful; however, these will lead to unwanted exposure to the disease burden [57, 76]. As Well, point-of-care echocardiography may be employed to assess regional myocardial contractile function and to guide decisions about invasive assessment [77].

\section{Markers of cardiac injury}

The elevated level of cardiac biomarkers in COVID-19 is a prominent feature that indicates cardiac involvement and is associated with poor clinical outcome [37, 78]. Elevated biomarkers of cardiac injury were detected in a significant number of admitted cases with COVID19. The prevalence is more in those with pre-existing cardiovascular disease [23, 43, 78]. High-sensitivity cardiac troponin I [hs-cTnI] level was elevated in COVID19 patients $(7.2 \%$ overall cases and $22 \%$ of critical care patients). Elevated troponin level was also detected in nearly $12 \%$ of COVID-19 patients with no previous history of CVD and was associated with poor prognosis $[6,43]$. A significant positive linear correlation between plasma TnT levels and plasma high sensitivity CRP levels indicates the close association between myocardial injury and the inflammatory process [23].

The levels of the biomarker of hemodynamic myocardial stress and HF which is B-Type Natriuretic Peptide/NTerminal B-Type Natriuretic Peptide (BNP/NT-proBNP) are commonly elevated among patients with severe inflammatory disorders including respiratory ones. The high levels of BNP/NT-proBNP in a patient with SARS$\mathrm{CoV}-2$ infection may suggest the presence/magnitude of pre-existing cardiac condition, especially the acute hemodynamic stress and/or the right ventricular strain linked to COVID-19 [78].

High levels of inflammatory markers of cardiac injury have been noted to be associated with electrocardiographic abnormalities in COVID-19 [23].

Significant coagulation abnormalities exist in hospitalized patients with severe COVID-19 illness [48]. D-dimer and fibrin degradation product (FDP) levels were significantly elevated in the non-surviving COVID-19 patients. Those who had high FDP fulfilled the diagnostic clinical parameters for disseminated intravascular coagulation [42]. A D-dimer level greater than $1 \mu \mathrm{g} / \mathrm{mL}$ during hospitalization was correlated with lethal outcomes [42, 43].

Furthermore, an abnormal immune response may be detected in COVID-19 patients as high expression of ACE2 receptors in the SARS-CoV-2 infected cells, high levels of IL-1, IL-6, IL-8, and IL-10 [18]. High levels of IL-6, LDH, ferritin, and D-dimer were all linked to myocardial injury [19].

\section{Implications on diagnosis}

The differential diagnosis of cardiovascular manifestations in presumed or evident COVID-19 infection is 
complicated and tricky. Various respiratory symptoms as shortness of breathing and chest pain are also cardiac symptoms. Dyspnea may also precede or associate other cardiac manifestations. Soon, a precise and quick determination of cardiovascular problems, in this case, is vital [35]. Clinicians should have a high index of clinical suspension of cardiac injury in the setting of COVID-19 pandemic. Prompt clinical evaluation is mandatory if cardiovascular involvement is suspected [46]. In individuals with acute illness who had recent cardiac symptoms, a thorough clinical examination and laboratory investigations, including troponin levels, are warranted. This will ensure appropriate recognition and prompt isolation of suspected cases and decrease the spread of infection [57].

\section{Implications on case management}

No specific treatment for COVID-19 has been reported or approved until the time of writing this review. The treatment is symptomatic, and some drugs were used due to their potential antiviral activity against different viruses rather than COVID-19.

It is important to protect the cardiovascular system in COVID-19 cases to prevent chronic cardiac damage [7].

The increased incidence of thromboembolic events in COVID-19 cases reported in several studies emphasized the benefits of using anticoagulants as a line of treatment in these cases. Low molecular weight heparin (LMWH) is commonly used in hospital settings and was associated with decreased morbidity and mortality [79]. Thromboprophylaxis was used only in those with a high risk of thrombosis [80]. However, some researchers suggested the administration of thromboprophylaxis in hospitalized COVID-19 to avoid the development of VTE and were found to be associated with better outcomes [81, 82].

The potential impact of acetylsalicylic acid (ASA) therapy has been questioned and still under investigation [83]. Nevertheless, the low doses of ASA have a minimal anti-inflammatory effect [84]. Those who use acetylsalicylic acid for long-term prevention of cardiovascular events are not advised to withhold it [85]. Nonsteroidal anti-inflammatory drugs (NSAIDs) could be a risk factor for the serious clinical presentation of COVID-19 [86]. The administration of NSAIDs may also hide some of the clinical manifestations leading to delayed diagnosis and treatment [85].

The acute treatment of arrhythmias and MI is similar to that in the general population. The same guidelines apply with consideration of the safety of healthcare professionals (HCP) [87, 88]. Primary percutaneous coronary intervention is the ideal decision for STEMI [64, 89], and in case of absence of personal protective equipment (PPE),

- ACEIs \& ARBs may have antiviral and immunoregulatory effect

- Patients receiving ACEIs/ARBs for hypertension were reported to have less severe disease, low levels of IL-6 and increased CD3 and CD8 levels in peripheral blood
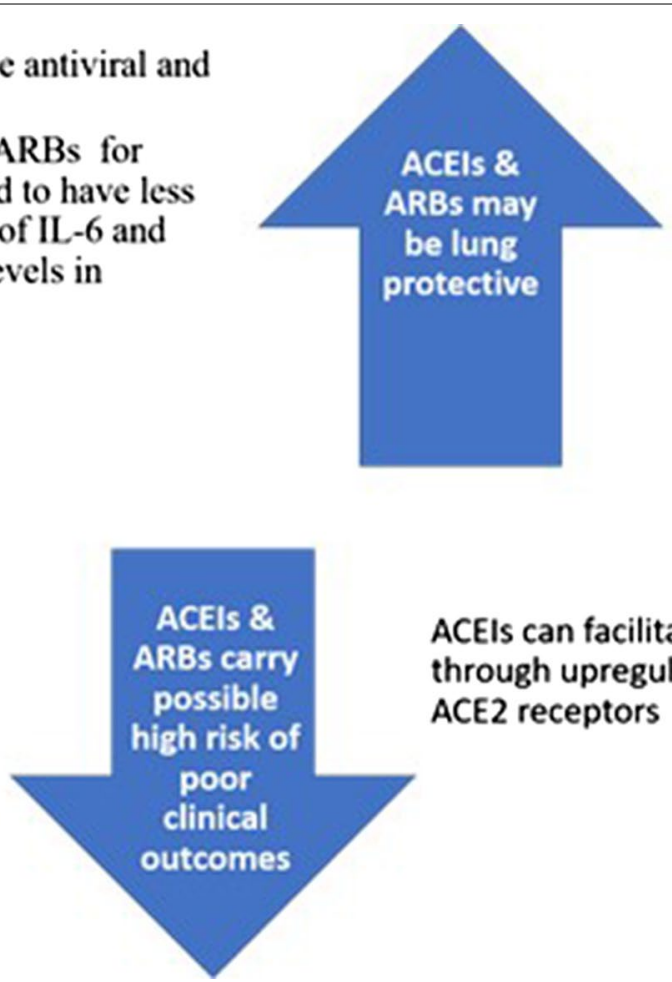

ACEIs can facilitate infection through upregulation of cardiac ACE2 receptors

Fig. 3 Controverse about the role of ACEIs \& ARBs in COVID-19: There is controverse about the use of ACEIs \& ARBs in COVID-19 


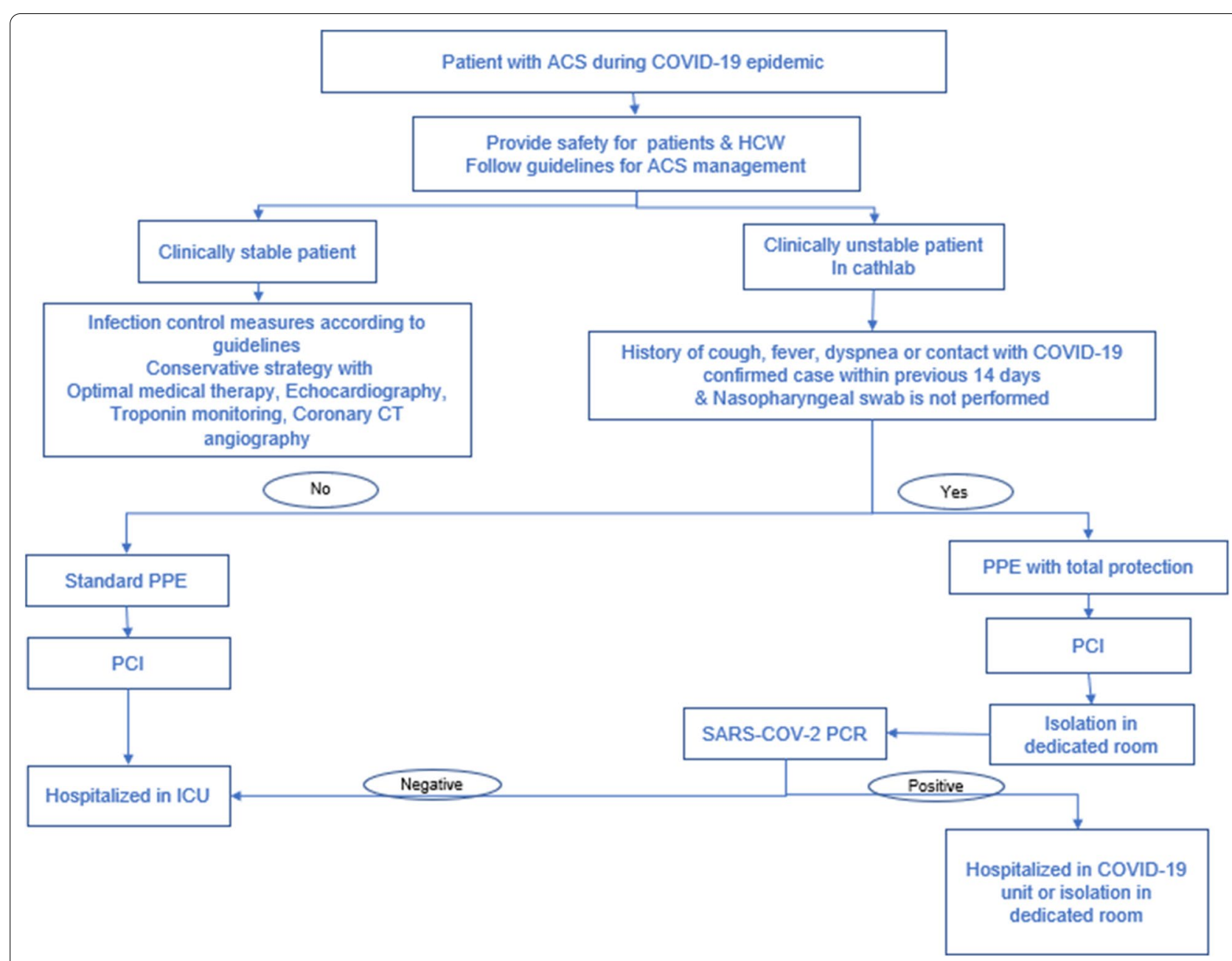

Fig. 4 Algorythm for management of acute coronay syndrome during COVID-19 epidemic. ACS: acute coronay Syndrome, ICU: intensive care unit, PPE: personal protective equipment, HCW: healthcare workers

fibrinolytic therapy may be an appropriate option [89, 90]. COVID-19 patients with non-ST-segment elevation myocardial infarction (NSTEMI) and who are hemodynamically unstable are managed as STEMI patients. Selected cases with NSTEMI and COVID-19 can undergo conservative therapy [77].

Adjusted fluid therapy management is critical in COVID-19 patients to avoid cardiovascular complications especially in those with ARDS who are liable to right heart failure [36].

There is an argument about the use of some drugs used for the treatment of CV diseases, especially RAS blocking drugs as ACEIs and angiotensin receptors blocking agents (ARBs) in patients with COVID-19 [91, 92] (Fig. 3), and the mechanism of involvement of these drugs in COVID-19 is still unclear involving several mediators, neural and chemical mechanisms. Some researchers suggested withholding ACEIs or ARBs in
COVID-19 patients and may be replaced by calcium channel blockers [46]. Their opinion is based on limited data supposing that ACEIs lead to upregulation of cardiac ACE2 receptors [93]. Controversy, more recent human studies reported no relationship between the use of these drugs and the severity, complications, and risk of death from COVID-19 after adjustment for other confounders [94-97]. Besides it may have immune-modulating effect [98-102], some studies reported no effect of ACEIs or ARBs on ACE receptors present in respiratory epithelium indicating no risk of increased susceptibility to COVID-19 infection [103]. At the current time, no evidence exists to support one of the two opposing opinions [91, 92]. So, discontinuation of RAAS in the setting of COVID-19 infection is not recommended $[104,105]$ as these drugs are key elements in the management of some cases [93]. Treatment of hypertension in COVID-19 
suspected or infected patients should continue to follow the current guidelines [105].

Statins have potential value in COVID-19. It may reduce risk of severe disease and hospitalization due to anti-inflammatory and immune modulating properties as well as antilipid effect as lipid metabolism contributes to pathogenesis of SARS-CoV-2 infection [106]. On the other hand, statins may lead to upregulation of ACE2 [107]. A recent metaanalysis concluded that statins could be of benefit in COVID-19 and no evidence against its use. However, randomized controlled trials of good quality are warranted to validate this conclusion [108].

Severe rhabdomyolysis or increased liver enzymes have been reported in some cases with COVID-19, and in such cases, it may be wise to stop statin therapy till the condition improves [82, 109].

Some drugs that are used in treatment protocols of COVID-19 may have some adverse events on the CVS or interact with drugs used for the treatment of $\mathrm{CV}$ conditions (Table 1). These drugs include lopinavir/ritonavir, remdesivir, chloroquine, and hydroxychloroquine.

Lopinavir/ritonavir may prolong PR and QT intervals in ECG, especially in the presence of baseline abnormalities like (long QT), risk of conduction abnormalities, and those receiving drugs that prolong QT interval [36]. Lopinavir/ritonavir has drug interactions with some anticoagulants, especially CYP3A-mediated drugs like rivaroxaban and apixaban. Dose reduction or avoidance of this group of drugs is recommended if lopinavir/ritonavir is used for treatment [36]. Remdesivir resulted in hypotension in some cases $[109,110]$. Chloroquine and hydroxychloroquine have cardiovascular side effects including cardiac arrhythmias either atrial or ventricular, HF, conduction abnormalities, cardiomyopathy, hypotension, and ECG changes including flat or inverted T wave, prolonged QT interval, wide QRS complex [110,111].

\section{Infection control measures}

For infection control purposes during the COVID-19 pandemic, diagnostic testing before any intervention is highly recommended [77]. Besides, in the absence of the SARS-CoV-2 testing results, they should be managed as if they are COVID-19 positive [88]. All HCP exposed to suspected/confirmed COVID-19 cases should adhere to infection control measures and wear appropriate PPE [11]. All non-urgent and/or elective investigational and/ or interventional procedures should be postponed till resolution of COVID-19 infection to avoid unnecessary exposure of HCP to the disease burden taking into consideration the balance between staff exposure and patient benefit $[11,57,75-77]$. In emergency cases where cardiac catheterization is indicated, it should be executed in a devoted COVID-19 catheterization laboratory if available [11] (Fig. 4). Careful decontamination of the cardiac intervention laboratories following the procedure is recommended. Rapid discharge is recommended after revascularization of patients with primary NSTEMI to reduce patient exposure within the hospital [77].

\section{Implications on public health}

Public health focuses on discovering and modernizing the environmental factors associated with diseases. The role of public health is on the individual or at the community level [112].

\section{Short-term effects and dilemma of resource allocation}

During the current pandemic, it is impossible to treat all patients, especially in critical care settings [113]. The need for rearrangement of healthcare services during the COVID-19 pandemic raised several issues regarding the prioritization of cardiovascular procedures to postpone procedures which are not urgent. An important issue is to put a strategy that guarantees that patients with emergency cardiac conditions will receive standard of care and had timely access to emergency services $[88,114]$. Allocation of HCR or redistribution

Table 1 Adverse events of some drugs used in treatment COVID-19 on cardiovascular system

\begin{tabular}{ll}
\hline Drug & Adverse CV effects \\
\hline Lopinavir/ritonavir [36] & ECG changes including prolonged PR and QT intervals \\
& Interactions with some anticoagulants especially CYP3A mediated drugs \\
Remdesivir $[109,110]$ & Hypotension \\
Chloroquine and hydroxychloroquine $[110,11]$ & Cardiac arrhythmias either atrial or ventricular, ventricular fibrillation \\
& Heart Failure, Atrioventricular block, bundle branch block \\
& Cardiomyopathy \\
& Hypotension \\
& ECG changes including flat or inverted T wave, prolonged QT interval, \\
& wide QRS complex \\
\hline
\end{tabular}


of healthcare services may intervene with decisionmaking. Resource allocation decisions often concentrate on the instant payoff for risk reduction from a specific disease. However, resource allocation decisions can impact the infrastructure required to respond over time to health risks [115]. So, we have faced by emerging ethical dilemmas: How healthcare resources (HCR) can be allocated?, how to put the HCR allocation guidelines? what do we rely on in the setting of the posterization for emergency health services? How many HCR allocation decisions will be carried out and how this will affect the delivery and distribution of health benefits? Which strategy will be used to deal with competing health policy priorities? $[113,116]$. Shall we allocate HCR to those who can be saved or those with the worst clinical situation? And why? [115].

Treatment strategies with controversial value will be a great challenge for HCR allocation decisions as some will see these strategies as life-saving and others see it of unproven efficacy and un-necessary action [117]. So, the two opposing public health values stewardship and compassion will appear. Whatever the best decision will be, most public health readers would like to present themselves to the community as dedicated to saving lives rather than conserving resources [115].

Usually, Medicine tells us what we can do; however, ethics tells us what we should do. Principles of medical ethics include: autonomy, beneficence, non-maleficence, and justice [118]. Generally, physicians/cardiologists follow one of three mechanisms: (i) external constraints, not admitting a patient from the ER who needs intensive care as all available beds are full and no patient can be safely discharged (e.g., all on ventilators). Or a patient who may need an emergency cardiac catheterization for an emergency coronary insufficiency but, the hospital's only interventional cardiologist is occupied in a lengthy procedure [119]. The second mechanism (ii) clinical guidelines set by the organization that may control the decision of clinicians when dealing with an emergency during pandemics, third mechanism is the (iii) clinical judgment which depends on the cardiologist experience; how to determine among competing patients who will receive the last bed or ventilator in the ICU. How to divide one's time among all of the patients in the ER or canceling surgery for a patient with the three-vessel disease and with "stable" angina [119].

Most guidelines and clinical practice procedures make prioritization of patients with chronic cardiac conditions like chronic coronary syndrome based on risk stratification [88, 114]. Initiation of invasive procedures for the emergency cardiac conditions like STEMI may be limited due to the high risk of infection and the need for prolonged disinfection after the procedures, and less effective procedures can be applied [11]. These modifications of optimal care may result in increased cardiovascular-related complications and deaths [120]. And access to emergency care may be negatively affected by the redistribution of healthcare resources and delayed arrival to emergency rooms as most patients are frightened from catching infection [11].

\section{Long-term effects}

The way of life and mental wellbeing sequel of COVID19 may increment the load of CVD. Lockdown and social distancing promote sedentary behavior, sudden alterations in lifestyle, and unhealthy diets [120]. The physical inactivity has deleterious effects including ectopic fat distribution, metabolic imbalance, impaired cardiorespiratory function, osteoporosis, weakness of lower extremity muscles [121, 122], hyperinsulinemia and increased insulin resistance, significant stress and anxiety, worsening depression, and loneliness $[120,123,124]$. The net result will be increased incidence of cardiovascular events, limited access to healthcare services for preventive measures, and overall increased healthcare expenditure [120]. This was very evident as a substantial upsurge in the occurrence of stress cardiomyopathy during the COVID19 pandemic. None of these patients was found to have COVID-19 disease suggesting indirect, psychological, social, and economic pandemic-related stress mechanisms behind the disease process [125].

\section{Implications on public health}

COVID-19 pandemic has several immediate and long-term cardiovascular complications. Cardiovascular diseases have deleterious effects on clinical outcomes. Overall cardiovascular health is affected by the COVID-19 pandemic either directly or indirectly. Clinicians should have a high index of suspension and be very cautious in drug selection during the management of COVID-19 cases. Cardiovascular emergencies in COVID-19 patients are managed similar to the general population with appropriate considerations to prevent transmission of infection.

\section{Conclusions}

COVID-19 is associated with negative consequences on the cardiovascular system. Meanwhile, preexisting cardiovascular complications are associated with poor prognosis. Knowing this fact should help improve local strategies set for management of cardiac problems during the COVID-19 pandemic.

\section{Abbreviations}

ACE2: Angiotensin-2; ACEls: Angiotensin-converting enzyme inhibitors; ACS: Acute coronary syndrome; AF: Atrial fibrillation; AMI: Acute myocardial 
infarction; ARBs: Angiotensin receptors blocking agents; ARDS: Acute respiratory distress syndrome; BNP: Brain natriuretic peptide; COPD: Chronic obstructive pulmonary disease; COVID-19: Coronavirus disease-2019; CRP: C-reactive protein; CS: Cardiogenic shock; CV: Cardiovascular; DM: Diabetes mellitus; ECG: Electrocardiography; FDP: Fibrin degradation product; HCP: Healthcare professionals; HCR: Healthcare resources; HF: Heart failure; hs-cTnl: High-sensitivity cardiac troponin I; ICU: Intensive care unit; IL: Interleukin; LMWH: Low molecular weight heparin; NSAIDs: Nonsteroidal anti-inflammatory drugs; NSTEMI: Non-ST-segment elevation myocardial infarction; NT-proBNP: N-Terminal B-type natriuretic peptide; PE: Pulmonary embolism; PPE: Personal protective equipment; RAS: Renin-angiotensin system; SARS-CoV-2: Severe acute respiratory syndrome coronavirus-2; STEMI: ST-segment elevation myocardial infarction; VTE: Venous thromboembolism.

\section{Acknowledgements}

Not applicable.

\section{Authors' contributions}

$E S, M R, T H, K A, S A, N M, N S, H A$ contributed to conception and design of the work, reviewing literature, manuscript writing and revision. ES wrote the first draft of the manuscript. ES, MR \& HA shared editing and critical revision. All authors read and accepted the final version to be published.

\section{Funding}

None.

\section{Declarations}

Ethics approval and consent to participate

Not applicable.

\section{Consent for publication}

Not applicable.

\section{Availability of data and material}

Not applicable.

\section{Competing interests}

The authors declare that they have no competing interests.

\section{Author details}

${ }^{1}$ Chest Diseases Department, Faculty of Medicine for Girls, Al-Azhar University, Cairo, Egypt. ${ }^{2}$ Respiratory Therapy Department, College of Medical Rehabilitation Sciences, Taibah University, Medina, Saudi Arabia. ${ }^{3}$ Cardiology Department, Faculty of Medicine, Al-Azhar University, Damietta, Egypt. ${ }^{4}$ Alghad International College of Applied Medical Sciences, Jeddah, Saudi Arabia. ${ }^{5}$ Public Health and Community Medicine Department, Faculty of Medicine, Beni-Suef University, Beni-Suef, Egypt. ${ }^{6}$ Biochemistry Unit, Chemistry Department, Faculty of Science, Damanhour University, Damanhour, Egypt. ${ }^{7}$ Independent Researcher, Bachelor Degree of Biochemistry, Faculty of Science, Cairo University, Cairo, Egypt. ${ }^{8}$ Faculty of Pharmacy, Al-Azhar University, Cairo, Egypt. ${ }^{9}$ Department of Medical Laboratory Technology, Faculty of Applied Medical Sciences, King Abdulaziz University, Jeddah 21589, Saudi Arabia. ${ }^{10}$ Special Infectious Agent Unit, King Fahd Medical Research Centre, King Abdulaziz University, Jeddah 21589, Saudi Arabia.

Received: 9 June 2021 Accepted: 18 August 2021

Published online: 03 September 2021

\section{References}

1. WHO Coronavirus (COVID-19) Dashboard|WHO Coronavirus (COVID-19) Dashboard With Vaccination Data [Internet]. [cited 2021 Aug 8]. https:// covid19.who.int/

2. Zhou P, Yang XL, Wang XG, Hu B, Zhang L, Zhang W et al (2020) A pneumonia outbreak associated with a new coronavirus of probable bat origin. Nature 579(7798):270-273

3. Gupta A, Madhavan MV, Sehgal K (2020) Extrapulmonary manifestations of COVID-19. Nat Med. https://doi.org/10.1038/s41591-020-0968-3
4. Elsalam A, El Barky KG, Mohamed AR (2020) Hepatic system management in COVID-19 infection. Ann Gastroenterol Dig Syst 3(1):1018

5. Madjid M, Safavi-Naeini P, Solomon SD, Vardeny O (2020) Potential effects of coronaviruses on the cardiovascular system: a review. JAMA Cardiol 5:831-840

6. Clerkin KJ, Fried JA, Raikhelkar J, Sayer G, Griffin JM, Masoumi A et al (2020) COVID-19 and cardiovascular disease. Circulation 141(20):16481655. https://doi.org/10.1161/CIRCULATIONAHA. 120.046941

7. Zheng YY, Ma YT, Zhang JY, Xie X (2020) COVID-19 and the cardiovascular system. Nat Rev Cardiol 17:259-260

8. Mahajan K, Chandra KS (2020) Cardiovascular comorbidities and complications associated with coronavirus disease 2019. Med J Armed Forces India 76:253-260

9. Parry AH, Wani AH, Yaseen M (2020) Pulmonary embolism in coronavirus disease-19 (COVID-19): rational and stepwise use of clinical data and imaging in its diagnosis. Clin Transl Imaging 1:3. https://doi.org/10. 1007/s40336-020-00380-2

10. Long B, Brady WJ, Koyfman A, Gottlieb M (2020) Cardiovascular complications in COVID-19. Am J Emerg Med 38:1504-1507

11. Society of Cardiology E. ESC Guidance for the Diagnosis and Management of CV Disease during the COVID-19 Pandemic [Internet]. 2020 [cited 2020 Sept 11]. https://www.escardio.org/Education/COVID-19and-Cardiology/ESC-COVID-19-Guidance

12. Baldi E, Sechi GM, Mare C, Canevari F, Brancaglione A, Primi R et al (2020) Out-of-hospital cardiac arrest during the COVID-19 outbreak in Italy. New Engl J Med 383:496-498

13. Andersen KG, Rambaut A, Lipkin WI, Holmes EC, Garry RF (2020) The proximal origin of SARS-CoV-2. Nat Med 26:450-452. https://doi.org/10. 1038/s41591-020-0820-9

14. Wrapp D, Wang N, Corbett KS, Goldsmith JA, Hsieh C-L, Abiona O et al (2019) Cryo-EM structure of the 2019-nCoV spike in the prefusion conformation. http://science.sciencemag.org/

15. Dong M, Zhang J, Ma X, Tan J, Chen L, Liu S et al (2020) ACE2, TMPRSS2 distribution and extrapulmonary organ injury in patients with COVID19. Biomed Pharmacother 131:110678

16. Gallagher PE, Ferrario CM, Tallant EA (2008) Regulation of ACE2 in cardiac myocytes and fibroblasts. Am J Physiol - Hear Circ Physiol 295(6):H2373

17. Hamming I, Timens W, Bulthuis MLC, Lely AT, Navis GJ, van Goor H (2004) Tissue distribution of ACE2 protein, the functional receptor for SARS coronavirus. A first step in understanding SARS pathogenesis. J Pathol 203(2):631-637

18. Li G, He X, Zhang L, Ran Q, Wang J, Xiong A et al (2020) Assessing ACE2 expression patterns in lung tissues in the pathogenesis of COVID-19. J Autoimmun 112:102463

19. Oudit GY, Kassiri Z, Jiang C, Liu PP, Poutanen SM, Penninger JM et al (2009) SARS-coronavirus modulation of myocardial ACE2 expression and inflammation in patients with SARS. Eur J Clin Investig 39(7):618-625

20. Puelles VG, Lütgehetmann M, Lindenmeyer MT, Sperhake JP, Wong MN, Allweiss $L$ et al (2020) Multiorgan and renal tropism of SARS-CoV-2. New Engl J Med 383:590-592

21. Ackermann M, Verleden SE, Kuehnel M, Haverich A, Welte T, Laenger $F$ et al (2020) Pulmonary vascular endothelialitis, thrombosis, and angiogenesis in Covid-19. N Engl J Med 383(2):120-128

22. Tavazzi G, Pellegrini C, Maurelli M, Belliato M, Sciutti F, Bottazzi A et al (2020) Myocardial localization of coronavirus in COVID-19 cardiogenic shock. Eur J Heart Fail 22(5):911-915. https://doi.org/10.1002/ejhf.1828

23. Guo T, Fan Y, Chen M, Wu X, Zhang L, He T et al (2020) Cardiovascular implications of fatal outcomes of patients with coronavirus disease 2019 (COVID-19). JAMA Cardiol 5(7):1

24. Coperchini F, Chiovato L, Croce L, Magri F, Rotondi M (2020) The cytokine storm in COVID-19: an overview of the involvement of the chemokine/chemokine-receptor system. Cytokine Growth Factor Rev 53:25-32

25. Xu Z, Shi L, Wang Y, Zhang J, Huang L, Zhang C et al (2020) Pathological findings of COVID-19 associated with acute respiratory distress syndrome. Lancet Respir Med 8(4):420-422

26. Sala S, Peretto G, Gramegna M, Palmisano A, Villatore A, Vignale D et al (2020) Acute myocarditis presenting as a reverse Tako-Tsubo 
syndrome in a patient with SARS-CoV-2 respiratory infection. Eur Heart J 41(19):1861-1862

27. Epelman S, Tang WHW, Chen SY, Van Lente F, Francis GS, Sen S (2008) Detection of soluble angiotensin-converting enzyme 2 in heart failure. Insights into the endogenous counter-regulatory pathway of the reninangiotensin-aldosterone system. J Am Coll Cardiol 52(9):750-754

28. Walters TE, Kalman JM, Patel SK, Mearns M, Velkoska E, Burrell LM (2017) Angiotensin converting enzyme 2 activity and human atrial fibrillation: increased plasma angiotensin converting enzyme 2 activity is associated with atrial fibrillation and more advanced left atrial structural remodelling. Europace 19(8):1280-1287

29. Repessé X, Vieillard-Baron A (2017) Right heart function during acute respiratory distress syndrome. Ann Transl Med 5:295

30. Biswas A (2015) Right heart failure in acute respiratory distress syndrome: An unappreciated albeit a potential target for intervention in the management of the disease. Indian J Crit Care Med 19(10):606-609

31. Ullah W, Saeed R, Sarwar U, Patel R, Fischman DL (2020) COVID-19 complicated by acute pulmonary embolism and right-sided heart failure. JACC Case Rep 2(9):1379-1382

32. Creel-Bulos C, Hockstein M, Amin N, Melhem S, Truong A, Sharifpour M (2020) Acute Cor pulmonale in critically ill patients with Covid-19. N Engl J Med 382(21):e70. https://doi.org/10.1056/NEJMc2010459

33. Tune JD (2007) Control of coronary blood flow during hypoxemia. Springer, Boston, MA, pp 25-39. https://doi.org/10.1007/ 978-0-387-75434-5_3

34. Heinonen IHA, Boushel R, Kalliokoski KK (2016) The circulatory and metabolic responses to hypoxia in humans - with special reference to adipose tissue physiology and obesity. Front Endocrinol 7:116

35. Thiele H, Ohman EM, De Waha-Thiele S, Zeymer U, Desch S (2019) Management of cardiogenic shock complicating myocardial infarction: an update 2019. Eur Heart J 40:2671-2683

36. Driggin E, Madhavan MV, Bikdeli B, Chuich T, Laracy J, Biondi-Zoccai $G$ et al (2020) Cardiovascular considerations for patients, health care workers, and health systems during the COVID-19 pandemic. J Am College Cardiol 75:2352-2371. https://doi.org/10.1016/j.jacc.2020.03.031

37. Huang C, Wang Y, Li X, Ren L, Zhao J, Hu Y et al (2020) Clinical features of patients infected with 2019 novel coronavirus in Wuhan, China. Lancet 395(10223):497-506

38. Chen N, Zhou M, Dong X, Qu J, Gong F, Han Y et al (2020) Epidemiological and clinical characteristics of 99 cases of 2019 novel coronavirus pneumonia in Wuhan, China: a descriptive study. Lancet 395(10223):507-513

39. Xiong TY, Redwood S, Prendergast B, Chen M (2020) Coronaviruses and the cardiovascular system: acute and long-term implications. Eur Heart J 41(19):1798-1800

40. Malavazos AE, Goldberger JJ, lacobellis G (2020) Does epicardial fat contribute to COVID-19 myocardial inflammation? Eur Heart J 41:2333

41. Cui S, Chen S, Li X, Liu S, Wang F (2020) Prevalence of venous thromboembolism in patients with severe novel coronavirus pneumonia. J Thromb Haemost 18(6):1421-1424. https://doi.org/10.1111/jth.14830

42. Tang N, Li D, Wang X, Sun Z (2020) Abnormal coagulation parameters are associated with poor prognosis in patients with novel coronavirus pneumonia. J Thromb Haemost 18(4):844-847

43. Zhou F, Yu T, Du R, Fan G, Liu Y, Liu Z et al (2020) Clinical course and risk factors for mortality of adult inpatients with COVID-19 in Wuhan, China: a retrospective cohort study. Lancet 395(10229):1054-1062

44. Li XC, Zhang J, Zhuo JL (2017) The vasoprotective axes of the reninangiotensin system: physiological relevance and therapeutic implications in cardiovascular, hypertensive and kidney diseases. Pharmacol Res 125:21-38

45. Wan Y, Shang J, Graham R, Baric RS, Li F (2020) Receptor recognition by the novel coronavirus from Wuhan: an analysis based on decade-long structural studies of SARS coronavirus. J Virol 94(7):e00127-20

46. Fang L, Karakiulakis G, Roth M (2020) Are patients with hypertension and diabetes mellitus at increased risk for COVID-19 infection? Lancet Respir Med 8:e21

47. Xie Y, Wang X, Yang P, Zhang S (2020) COVID-19 complicated by acute pulmonary embolism. Radiol Cardiothorac Imaging 2(2):e200067. https://doi.org/10.1148/ryct.2020200067
48. Klok FA, Kruip MJHA, van der Meer NJM, Arbous MS, Gommers DAMPJ, Kant KM et al (2020) Incidence of thrombotic complications in critically ill ICU patients with COVID-19. Thromb Res 191:145

49. Tal S, Spectre G, Kornowski R, Perl L (2020) Venous thromboembolism complicated with COVID-19: what do we know so far? Acta Haematol 143(5):1-8

50. Muhammad DG, Abubakar IA (2021) COVID-19 lockdown may increase cardiovascular disease risk factors. Egypt Heart J 73:1-3. https://doi.org/ 10.1186/s43044-020-00127-4

51. Wu Z, McGoogan JM (2020) Characteristics of and important lessons from the coronavirus disease 2019 (COVID-19) outbreak in China: summary of a report of 72314 cases from the Chinese Center for Disease Control and Prevention. JAMA - J Am Med Assoc 323:1239-1242

52. Booth CM (2003) Clinical features and short-term outcomes of 144 patients with SARS in the greater Toronto area. JAMA 289(21):2801. https://doi.org/10.1001/jama.289.21.JOC30885

53. Badawi A, Ryoo SG (2016) Prevalence of comorbidities in the Middle East respiratory syndrome coronavirus (MERS-CoV): a systematic review and meta-analysis. Int J Infect Dis 49:129-133

54. Böhm M, Frey N, Giannitsis E, Sliwa K, Zeiher AM (2020) Coronavirus Disease 2019 (COVID-19) and its implications for cardiovascular care: expert document from the German Cardiac Society and the World Heart Federation. Clin Res Cardiol 109:1446-1459

55. Kirkpatrick JN, Mitchell C, Taub C, Kort S, Hung J, Swaminathan M (2020) ASE statement on protection of patients and echocardiography service providers during the 2019 novel coronavirus outbreak: endorsed by the American College of Cardiology. J Am Soc Echocardiogr 33(6):648-653

56. Feature | Management of the Hospitalized COVID-19 Patient With Acute Cardiomyopathy or Heart Failure - American College of Cardiology [Internet]. [cited 2020 Sep 12]. https://www.acc.org/latest-in-cardi ology/articles/2020/04/16/14/42/management-of-the-hospitaliz ed-covid-19-coronavirus-2019-patient-with-acute-cardiomyopathy-orheart-failure

57. Inciardi RM, Lupi L, Zaccone G, Italia L, Raffo M, Tomasoni D et al (2020) Cardiac involvement in a patient with coronavirus disease 2019 (COVID19). JAMA Cardiol 5(7):819-824

58. Yang $X, Y u Y, X u J$, Shu H, Xia J, Liu H et al (2020) Clinical course and outcomes of critically ill patients with SARS-CoV-2 pneumonia in Wuhan, China: a single-centered, retrospective, observational study. Lancet Respir Med 8(5):475-481

59. Ruan Q, Yang K, Wang W, Jiang L, Song J (2020) Clinical predictors of mortality due to COVID-19 based on an analysis of data of 150 patients from Wuhan, China. Intensive Care Med 46:846-848

60. Wang D, Hu B, Hu C, Zhu F, Liu X, Zhang J et al (2020) Clinical characteristics of 138 hospitalized patients with 2019 novel coronavirusinfected pneumonia in Wuhan, China. JAMA - J Am Med Assoc 323(1 1):1061-1069

61. Thygesen K, Alpert JS, Jaffe AS, Chaitman BR, Bax JJ, Morrow DA et al (2019) Fourth universal definition of myocardial infarction (2018). Eur Heart J 40(3):237-269

62. Fried JA, Ramasubbu K, Bhatt R, Topkara VK, Clerkin KJ, Horn E et al (2020) The variety of cardiovascular presentations of COVID-19. Circulation 141(23):1930-1936

63. Kwong JC, Schwartz KL, Campitelli MA, Chung H, Crowcroft NS, Karnauchow T et al (2018) Acute myocardial infarction after laboratoryconfirmed influenza infection. N Engl J Med 378(4):345-353. https://doi. org/10.1056/NEJMoa1702090

64. Mahmud E, Dauerman HL, Welt FGP, Messenger JC, Rao SV, Grines C et al (2020) Management of acute myocardial infarction during the COVID-19 pandemic: a Consensus Statement from the Society for Cardiovascular Angiography and Interventions (SCAI), the American College of Cardiology (ACC), and the American College of Emergency Physicians (ACEP). Catheter Cardiovasc Interv 96(2):336-345

65. Tomasoni D, Italia L, Adamo M, Inciardi RM, Lombardi CM, Solomon SD et al (2020) COVID-19 and heart failure: from infection to inflammation and angiotensin II stimulation. Searching for evidence from a new disease. Eur J Heart Fail 22(6):957-966. https://doi.org/10.1002/ejhf.1871

66. Liu K, Fang YY, Deng Y, Liu W, Wang MF, Ma JP et al (2020) Clinical characteristics of novel coronavirus cases in tertiary hospitals in Hubei Province. Chin Med J (Engl) 133(9):1025-1031 
67. Yang C, Jin Z (2020) An acute respiratory infection runs into the most common noncommunicable epidemic-COVID-19 and cardiovascular diseases. JAMA Cardiol 5:743-744

68. Bompard F, Monnier H, Saab I, Tordjman M, Abdoul H, Fournier L et al (2020) Pulmonary embolism in patients with COVID-19 pneumonia. Eur Respir J 56:2001365

69. Grillet F, Behr J, Calame P, Aubry S, Delabrousse E (2020) Acute pulmonary embolism associated with COVID-19 pneumonia detected with pulmonary CT angiography. Radiology 296(3):E186-E188

70. Dolhnikoff M, Duarte-Neto AN, de Almeida Monteiro RA, da Silva LFF, de Oliveira EP, Saldiva PHN et al (2020) Pathological evidence of pulmonary thrombotic phenomena in severe COVID-19. J Thromb Haemost 18:1517-1519

71. Abou-Ismail MY, Diamond A, Kapoor S, Arafah Y, Nayak L (2020) The hypercoagulable state in COVID-19: incidence, pathophysiology, and management. Thromb Res 194:101

72. Shirazi S, Mami S, Mohtadi N, Ghaysouri A, Tavan H, Nazari A et al (2020) Sudden cardiac death in COVID-19 patients, a report of three cases. Future Cardiol. https://doi.org/10.2217/fca-2020-0082

73. Richardson S, Hirsch JS, Narasimhan M, Crawford JM, McGinn T, Davidson KW et al (2020) Presenting characteristics, comorbidities, and outcomes among 5700 patients hospitalized with COVID-19 in the New York City Area. JAMA - J Am Med Assoc 323(20):2052-2059

74. HRS COVID-19 Task Force Update: April 7, 2020 | Heart Rhythm Society [Internet]. [cited 2020 Sep 12]. https://www.hrsonline.org/COVID19Challenges-Solutions/hrs-covid-19-task-force-message-qtc-guidance

75. Skulstad H, Cosyns B, Popescu BA, Galderisi M, Salvo GD, Donal E et al (2020) COVID-19 pandemic and cardiac imaging: EACVI recommendations on precautions, indications, prioritization, and protection for patients and healthcare personnel. Eur Heart J Cardiovasc Imaging 21(6):592-598

76. Wang C, Horby PW, Hayden FG, Gao GF (2020) A novel coronavirus outbreak of global health concern. The Lancet 395:470-473. https://doi. org/10.1016/S0140-6736

77. Welt FGP, Shah PB, Aronow HD, Bortnick AE, Henry TD, Sherwood MW et al (2020) Catheterization laboratory considerations during the coronavirus (COVID-19) pandemic: from the ACC's Interventional Council and SCAI. J Am Coll Cardiol 75(18):2372-2375

78. Shi S, Qin M, Shen B, Cai Y, Liu T, Yang F et al (2020) Association of cardiac injury with mortality in hospitalized patients with COVID-19 in Wuhan, China. JAMA Cardiol 5(7):802-810

79. Komiyama M, Hasegawa K (2020 Anticoagulant therapy for patients with coronavirus disease 2019: urgent need for enhanced awareness. Eur Cardiol Rev 7:15

80. Tang N, Bai H, Chen X, Gong J, Li D, Sun Z (2020) Anticoagulant treatment is associated with decreased mortality in severe coronavirus disease 2019 patients with coagulopathy. J Thromb Haemost 18(5):1094-1099. https://doi.org/10.1111/jth.14817

81. Connors JM, Levy JH (2020) COVID-19 and its implications for thrombosis and anticoagulation. Blood 135(23):2033-2040

82. Lodigiani C, lapichino G, Carenzo L, Cecconi M, Ferrazzi P, Sebastian Tet al (2020) Venous and arterial thromboembolic complications in COVID-19 patients admitted to an academic hospital in Milan, Italy. Thromb Res 191:9-14

83. Bianconi V, Violi F, Fallarino F, Pignatelli P, Sahebkar A, Pirro M (2020) Is acetylsalicylic acid a safe and potentially useful choice for adult patients with COVID-19 ? Drugs. https://doi.org/10.1007/s40265-020-01365-1

84. Talasaz AH, Kakavand H, Van Tassell B, Aghakouchakzadeh M, Sadeghipour P, Dunn S et al (2020) Cardiovascular complications of COVID19: pharmacotherapy perspective. Cardiovasc Drugs Ther 35(2):249-259

85. Little $P(2020)$ Non-steroidal anti-inflammatory drugs and covid-19. The BMJ 368:m1185

86. Basille D, Plouvier N, Trouve C, Duhaut P, Andrejak C, Jounieaux V (2017) Non-steroidal anti-inflammatory drugs may worsen the course of community-acquired pneumonia: a cohort study. Lung 195(2):201-208

87. Brugada J, Katritsis DG, Arbelo E, Arribas F, Bax JJ, Blomstrom-Lundqvist C et al (2020) 2019 ESC Guidelines for themanagement of patients with supraventricular tachycardia. Eur Heart J 41(5):655-720

88. Stefanini GG, Azzolini E, Condorelli G (2020) Critical organizational issues for cardiologists in the COVID-19 outbreak: a frontline experience from Milan, Italy. Circulation 141:1597-1599
89. Ranard LS, Ahmad Y, Masoumi A, Chuich T, Romney MLS, Gavin N et al (2020) Clinical pathway for management of suspected or positive novel coronavirus-19 patients with ST-segment elevation myocardial infarction. Crit Pathw Cardiol 19(2):49-54

90. Lee WH, Chen YC, Chen SC, Chen CJ, Hsu PC, Tsai WC et al (2020) Cardiovascular disease management during the coronavirus disease 2019 pandemic. Int J Med Sci 17:1340-1344

91. Patel AB, Verma A (2020) COVID-19 and angiotensin-converting enzyme inhibitors and angiotensin receptor blockers: what is the evidence? JAMA - J Am Med Assoc 323:1769-1770

92. Vaduganathan M, Vardeny O, Michel T, McMurray JJV, Pfeffer MA, Solomon SD (2020) Renin-angiotensin-aldosterone system inhibitors in patients with covid-19. N Engl J Med 382(17):1653-1659

93. Tadic M, Cuspidi C, Mancia G, Dell'Oro R, Grassi G (2020) COVID-19, hypertension and cardiovascular diseases: should we change the therapy? Pharmacol Res 158:104906

94. Reynolds HR, Adhikari S, Pulgarin C, Troxel AB, Iturrate E, Johnson SB et al (2020) Renin-angiotensin-aldosterone system inhibitors and risk of covid-19. N Engl J Med 382(25):2441-2448

95. Mancia G, Rea F, Ludergnani M, Apolone G, Corrao G (2020) Reninangiotensin-aldosterone system blockers and the risk of COVID-19. N Engl J Med 382(25):2431-2440

96. Li J, Wang X, Chen J, Zhang H, Deng A (2020) Association of reninangiotensin system inhibitors with severity or risk of death in patients with hypertension hospitalized for coronavirus disease 2019 (COVID-19) infection in Wuhan, China. JAMA Cardiol 5(7):825-830

97. de Abajo FJ, Rodríguez-Martín S, Lerma V, Mejía-Abril G, Aguilar M, García-Luque A et al (2020) Use of renin-angiotensin-aldosterone system inhibitors and risk of COVID-19 requiring admission to hospital: a case-population study. Lancet 395(10238):1705-1714

98. Kuba K, Imai Y, Rao S, Gao H, Guo F, Guan B et al (2005) A crucial role of angiotensin converting enzyme 2 (ACE2) in SARS coronavirusinduced lung injury. Nat Med 11(8):875-879

99. Zhang P, Zhu L, Cai J, Lei F, Qin JJ, Xie J et al (2020) Association of inpatient use of angiotensin-converting enzyme inhibitors and angiotensin II receptor blockers with mortality among patients with hypertension hospitalized with COVID-19. Circ Res 126(12):1671-1681

100. Yang G, Yang G, Tan Z, Tan Z, Zhou L, Yang M et al (2020) Effects of angiotensin II receptor blockers and ACE (angiotensin-converting enzyme) inhibitors on virus infection, inflammatory status, and clinical outcomes in patients with COVID-19 and hypertension: a singlecenter retrospective study. Hypertension 76(1):51-58

101. Imai Y, Kuba K, Rao S, Huan Y, Guo F, Guan B et al (2005) Angiotensinconverting enzyme 2 protects from severe acute lung failure. Nature 436(7047):112-116

102. Meng J, Xiao G, Zhang J, He X, Ou M, Bi J et al (2020) Renin-angiotensin system inhibitors improve the clinical outcomes of COVID-19 patients with hypertension. Emerg Microbes Infect 9:757-760

103. ACE2 localizes to the respiratory cilia and is not increased by ACE inhibitors or ARBs | Nature Communications [Internet]. [cited 2021 Aug 9]. https://www.nature.com/articles/s41467-020-19145-6

104. Murthy VL, Koupenova M, Shah RV (2020) ACEing COVID-19: a role for angiotensin axis inhibition in SARS-CoV-2 infection? Circ Res 126:1682-1684. https://doi.org/10.1161/CIRCRESAHA.120.317174

105. Position Statement of the ESC Council on Hypertension on ACEInhibitors and Angiotensin Receptor Blockers [Internet]. [cited 2020 Sept 12]. https://www.escardio.org/Councils/Council-on-Hypertensi on-(CHT)/News/position-statement-of-the-esc-council-on-hyper tension-on-ace-inhibitors-and-ang

106. Fajgenbaum DC, Rader DJ (2020) Teaching old drugs new tricks: statins for COVID-19? Cell Metab 32(2):145-147

107. Shin YH, Min JJ, Lee JH, Kim EH, Kim GE, Kim MH et al (2017) The effect of fluvastatin on cardiac fibrosis and angiotensin-converting enzyme-2 expression in glucose-controlled diabetic rat hearts. Heart Vessels 32(5):618-627. https://doi.org/10.1007/s00380-016-0936-5

108. Kow CS, Hasan SS (2020) Meta-analysis of effect of statins in patients with COVID-19. Am J Cardiol 134:153-155

109. Grein J, Ohmagari N, Shin D, Diaz G, Asperges E, Castagna A et al (2020) Compassionate use of remdesivir for patients with severe 
COVID-19. N Engl J Med 382(24):2327-2336. https://doi.org/10.1056/ NEJMoa2007016

110. Chloroquine (Professional Patient Advice)—Drugs.com [Internet]. [cited 2020 Sept 12]. https://www.drugs.com/ppa/chloroquine.html

111. Hydroxychloroquine (Professional Patient Advice) - Drugs.com [Internet]. [cited 2020 Sept 12]. https://www.drugs.com/ppa/hydroxychl oroquine.html

112. WHO | Public health programmes and social determinants

113. Savulescu J, Persson I, Wilkinson D (2020) Utilitarianism and the pandemic. Bioethics 34(6):620-632. https://doi.org/10.1111/bioe.12771

114. Neumann FJ, Sousa-Uva M, Ahlsson A, Alfonso F, Banning AP, Benedetto $U$ et al (2019) 2018 ESC/EACTS Guidelines on myocardial revascularization. Eur Heart J 40:87-165

115. Daniels N (2016) Resource allocation and priority setting. In: Barrett DH, Ortmann LW, Dawson A, Saenz C, Reis A, Bolan G (eds) Public health ethics analysis. Springer, Cham, pp 61-94

116. Savulescu J, Cameron J, Wilkinson D (2020) Equality or utility? Ethics and law of rationing ventilators. Br J Anaesthesia 125:10-15

117. Chapter 7: current and emerging health protection issues-GOV.UK

118. Medical Ethics Explained: Justice-The Medic Portal

119. Stelfox HT, Perrier L, Straus SE, Ghali WA, Zygun D, Boiteau P et al (2013) Identifying intensive care unit discharge planning tools: protocol for a scoping review. BMJ Open 3(4):e002653

120. Carter P, Anderson M, Mossialos E (2020) Health system, public health, and economic implications of managing COVID-19 from a cardiovascular perspective. Eur Heart J 41 (27):2516-2518
121. Oikawa SY, Holloway TM, Phillips SM (2019) The impact of step reduction on muscle health in aging: protein and exercise as countermeasures. Front Nutr 6:75

122. Bowden Davies KA, Pickles S, Sprung VS, Kemp GJ, Alam U, Moore DR et al (2019) Reduced physical activity in young and older adults: metabolic and musculoskeletal implications. Ther Adv Endocrinol Metab 10:204201881988882. https://doi.org/10.1177/2042018819888824

123. Füzéki E, Groneberg DA, Banzer W (2020) Physical activity during COVID-19 induced lockdown: recommendations. J Occup Med Toxicol 15(1):25. https://doi.org/10.1186/s12995-020-00278-9

124. Carvalho Aguiar Melo M, de Sousa Soares D (2020) Impact of social distancing on mental health during the COVID-19 pandemic: an urgent discussion. Int J Soc Psychiatry 66:625-626. https://doi.org/10.1177/ 0020764020927047

125. Jabri A, Kalra A, Kumar A, Alameh A, Adroja S, Bashir H et al (2020) Incidence of stress cardiomyopathy during the coronavirus disease 2019 pandemic. Jama Netw Open 3(7):e2014780

\section{Publisher's Note}

Springer Nature remains neutral with regard to jurisdictional claims in published maps and institutional affiliations.

\section{Submit your manuscript to a SpringerOpen ${ }^{\circ}$ journal and benefit from:}

- Convenient online submission

- Rigorous peer review

- Open access: articles freely available online

- High visibility within the field

- Retaining the copyright to your article

Submit your next manuscript at $\boldsymbol{\nabla}$ springeropen.com 